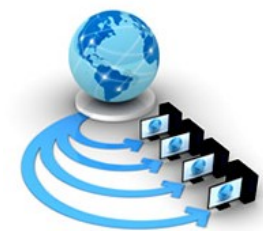

Volume 9, No. 6, November-December 2018

\title{
ONLINE ORDERING AND PAYMENT SYSTEM WITH SMS NOTIFICATION FOR NINA CLOTHING ACCESSORIES
}

\author{
Ronaldo Dante C. Vega*,Princess Marlene Novila,Regine L. Ibañez,Marjorie P. Teñido And Louie F. Agustin \\ *College of Computer Studies, Trimex Colleges, \\ Biñan, Laguna, Philippines
}

\begin{abstract}
Online payment remains a significant factor in today's e-business sector. Since businesses are expanding globally and also offering online options, the need for alternative forms of payment is quite substantial. The use of online payment systems has increased substantially and has changed the way consumers do business. Online payment systems have also catalysed new business formations and social practices. The term electronic money was formed from online payment systems, electronic ordering and payment system. The Online Ordering and Payment System with SMS Notification for Nina Clothing Accessories is a system that can order through online. The admin part of the system can monitor sales order including customer's information. The customer would find their experience most enhanced when the online system gives flexibility for the customer to choose the delivery method and receive the SMS Notification on the ordering status.
\end{abstract}

Keywords: Online Ordering; Payment System; SMS Notification; Internet; Android Mobile Phone

\section{INTRODUCTION}

Nina Clothing \& Accessories started as a boutique shop in one of the alleyways of Biñan, Laguna. It was an entrepreneurial venture of Nina Sigua the owner as a product of her love for fashion. Through her hard work and dedication, Nina Clothing \& Accessories is now strategically located along the busy street of Gen. Capinpin in Biñan, Laguna, one of the main roads of the city. Aside from the Physical Store, Nina Clothing and Accessories has its remarkable online presence in Social Media, both on Instagram and Facebook. This is to competitively cater the fast demand of both fashion and technology. It has 22 thousands followers on Instagram and 7 thousands followers on Facebook.

Currently, Nina Clothing \& Accessories is in its 4th year in business and perpetually growing. The marketing strategy that they are currently using isn't very effective, so they want to expand and improve their business using Online Ordering and Payment System with SMS Notification.

Its main aim is to simplify and improve the efficiency of the ordering process for both customer and clothing apparel. Minimize manual data entry and ensure data accuracy and security during order placement process. Customers will also be able to view product menus and be able to have a visual confirmation that the order was place correctly and they can also view the products using an Android app.

The Online Ordering and Payment System with SMS Notification for Nina Clothing \& Accessories is a computer based for the online buyer. It can easily to order via online because the other/s who wants to order/s but they have no time for going to the store it will be easy to buy their want/s.

It can also notify the customer via SMS if his/her order accepted by the admin and its ready for the delivery.
Regarding to the payment it will be easily to pay via G-Cash or PayPal.

\subsection{DESIGN OF THE STUDY}

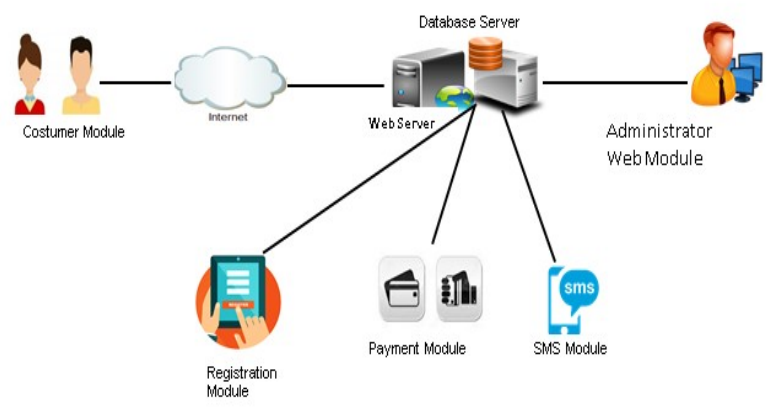

Figure 1 System Architecture

The figure above shows the different components of Online Ordering and Payment System with SMS Notification for Nina Clothing Accessories. There will be users like the Administrator, who administer user's reports and who will manage the sending of SMS for payment advisories. 


\subsection{DATABASE SCHEMA}

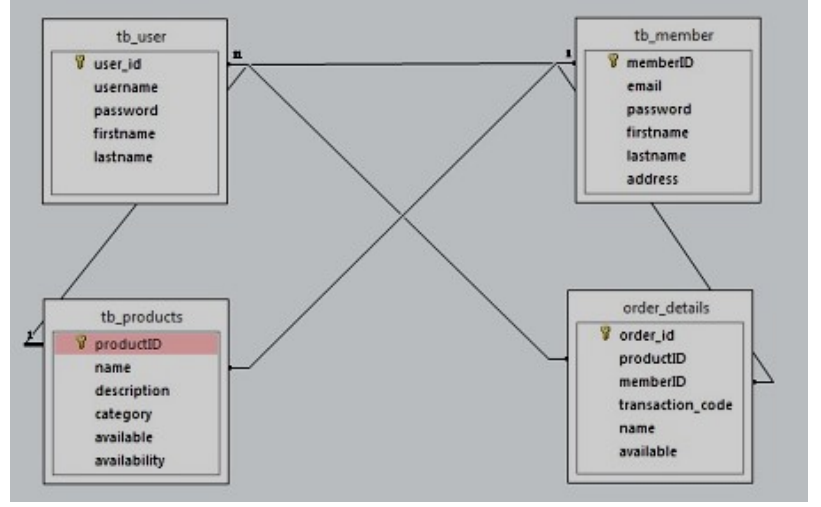

Figure 2 Database Schema

This figure shows the database design of the proposed system. The database name is dbsample and is consists of 8 tables.

\subsection{USE CASE DIAGRAM}

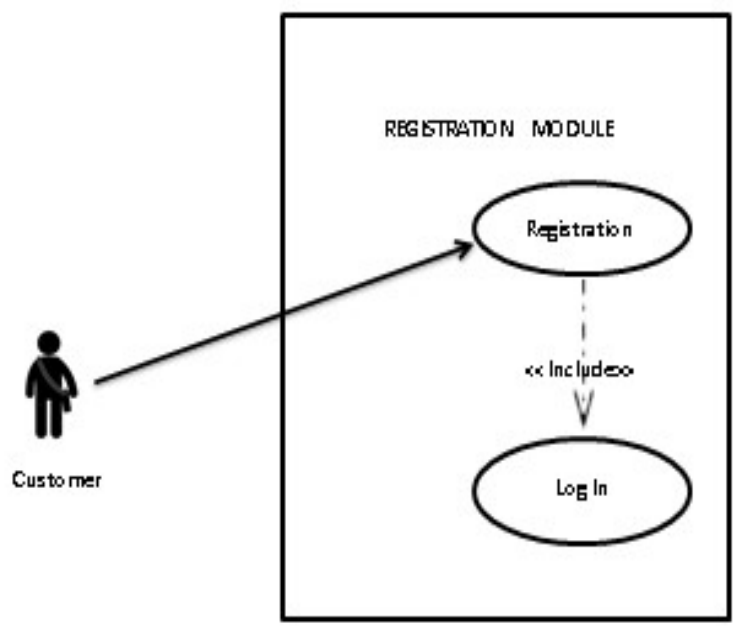

Figure 3 Use Case Diagram of Registration

As the registration module, the customer need to register all the information that the Admin want to know about her/his order and the information that where she/he is. After registering of the customer he/she needs to $\log$ in to know that he/she is a customer of the clothing shop.

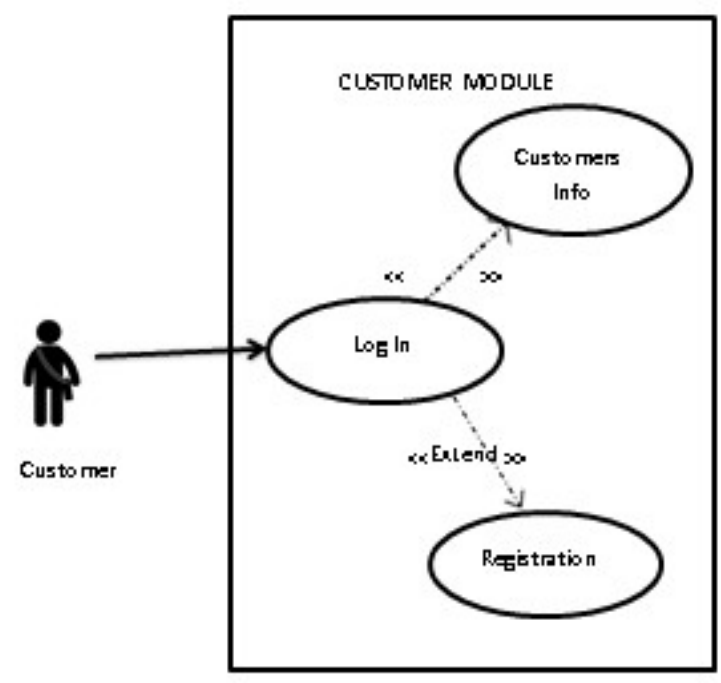

Figure 4 Use Case Diagram of Customer

As the customer module, the customer needs to login first to show the information about him/her. This account will be updating his/her personal information and orders if he/she wants to change it.

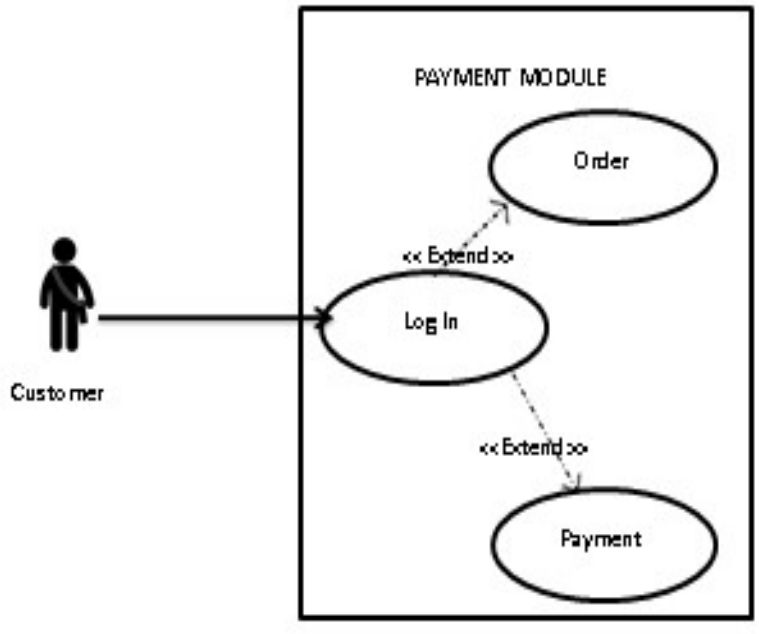

Figure 5 Use Case Diagram of Payment

The figure shows that the customer needs to login to make an order and pay it in wherever he/she wants it can be G-Cash, PayPal or COD. 


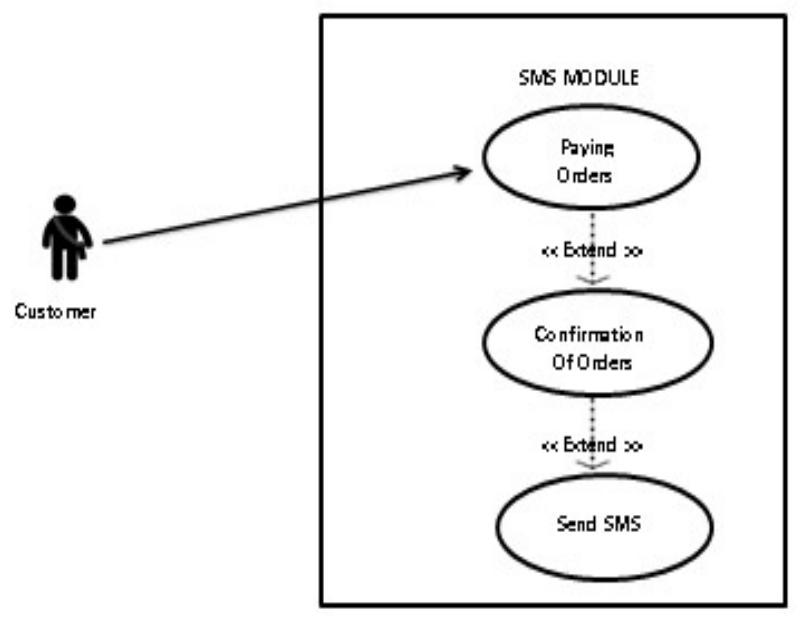

Figure 6 Use Case Diagrams of SMS

As the SMS module diagram show, the customer will pay the orders and as the admin confirm his/her orders, the costumer will receive a message that will notify the customer as the admin receive his/her payment and orders.

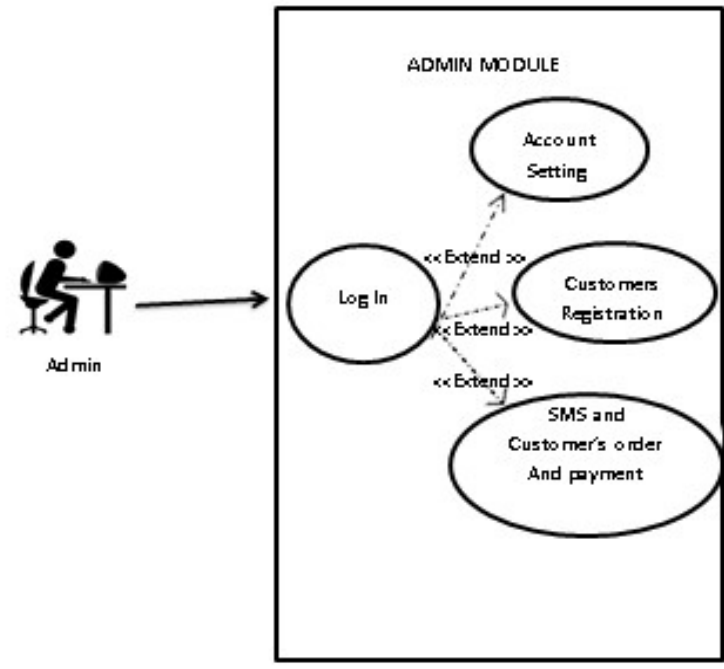

Figure 7 Use Case Diagram of Admin

As the admin module show, the admin can accept and register of customer and sending SMS. Upon ordering the costumer will create his/her account as a customer and fill out registration forms, the admin can monitor the orders of the customer. The admin also add an account for his/her report and the admin is the one who is responsible for sending SMS Payment notifications and cancellation of orders.

\section{LITERATURE SURVEY}

According to the Authors, to develop this Online Ordering and Payment System with SMS Notification for Nina Clothing \& Accessories [1] that can order through online. It can also transact the payment through this online website. The admin part of the system will manage by the owner of this website.

According to the Authors, to this system the Online Ordering and Payment System with SMS Notification for
Nina Clothing \& Accessories [2] is a computer based for the online buyer. It can easily to order via online because the other/s who wants to order/s but they have no time for going to the store it will be easy to buy their want/s.

According to the Authors, to develop this Online Ordering and Payment System with SMS Notification for Nina Clothing \& Accessories [3] that can notify the customer via SMS if his/her order accepted by the admin and it's ready for the delivery. Regarding to the payment it will be easily to pay via G-Cash or PayPal.

\section{FLOW CHART}

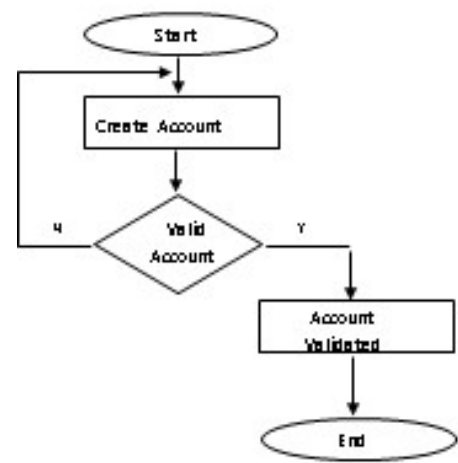

Figure 8 Customer

A customer should create an account by registering all his/her information. The online ordering system will validate the customer's account. After validation, the customer can now view the website and order.

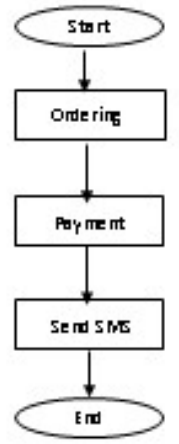

Figure 9 SMS

After ordering, the customer will receive a message and can pay it. In every time that the customer order and pay he/she will receive a message from the admin. 


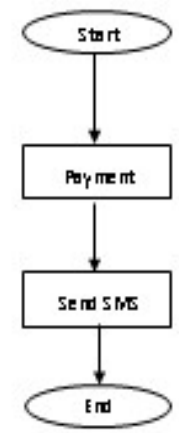

Figure 10 Payment

After the customer ordered they will pay it wherever he/she wants. It's PayPal, Bank Deposit or Cash on Delivery.

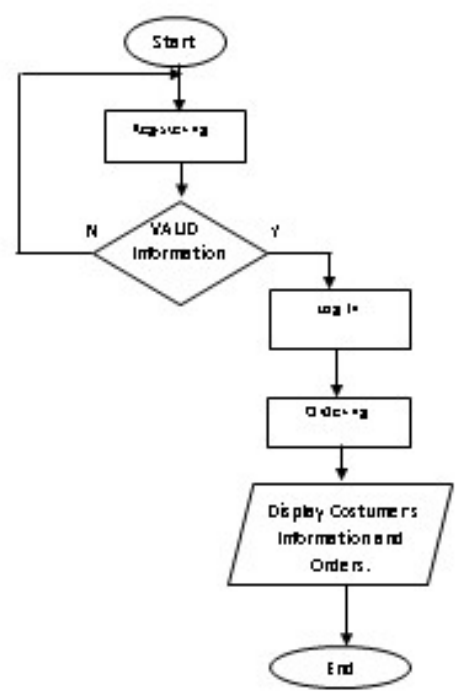

Figure 11 Registration

Process the Registration:

1. Check the entire costumer's information Validity.

2. The customer can now log in.

3. The customer will order.

4. Display the customer's information and orders.

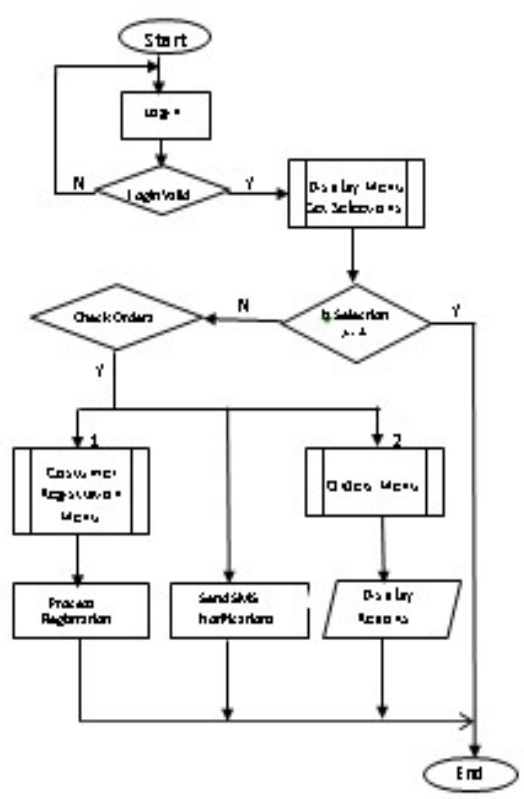

Figure 12 Administrator

The administrator will log in to the web page. If you go to the Customer section, be registered included. The orders report can also be generated base on your selected customer account.
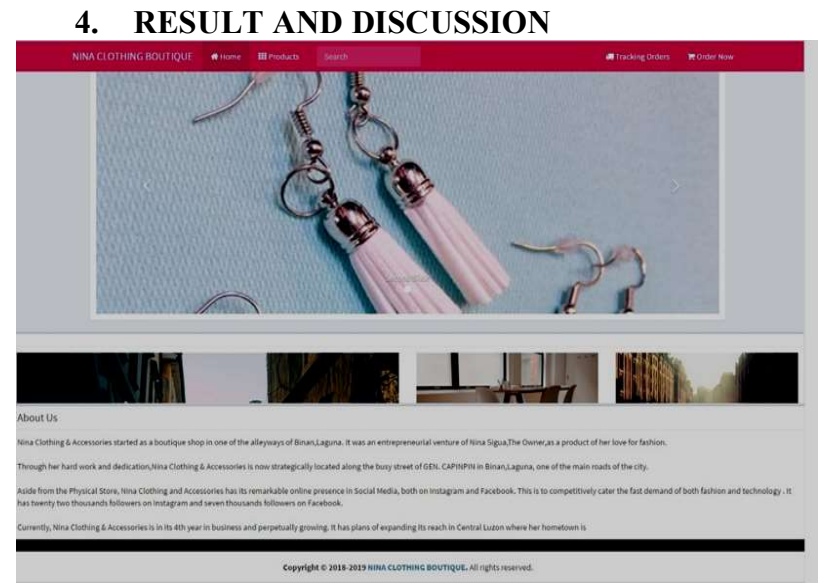

Figure 13 Home page

The first figure shows the homepage of the system. The first objective of the study is to create a module that will accept orders through online. 


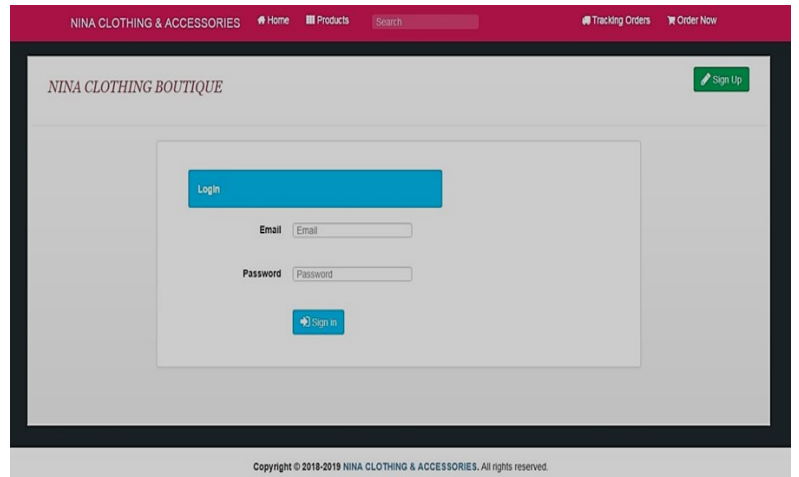

Figure 14 Log in

The figure above shows the log in. The customers need to have an account before he/she can order.

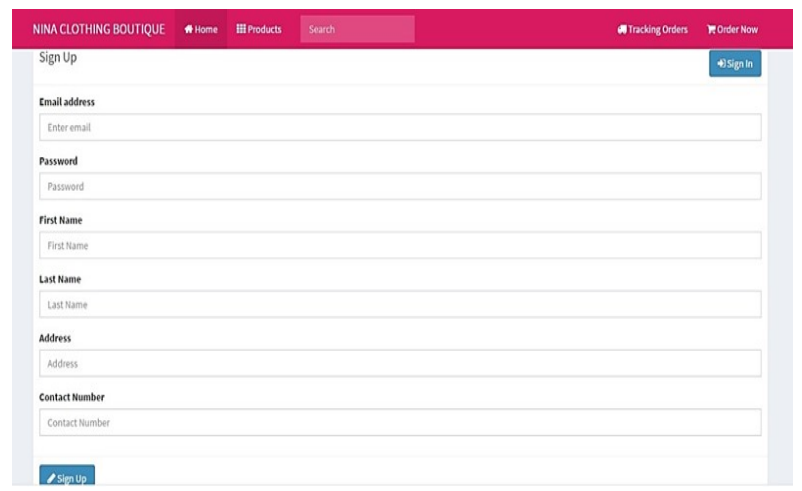

Figure 15 Sign up

The figure above shows the sign-up form, if the customer has no account yet he/she can fill up the form.

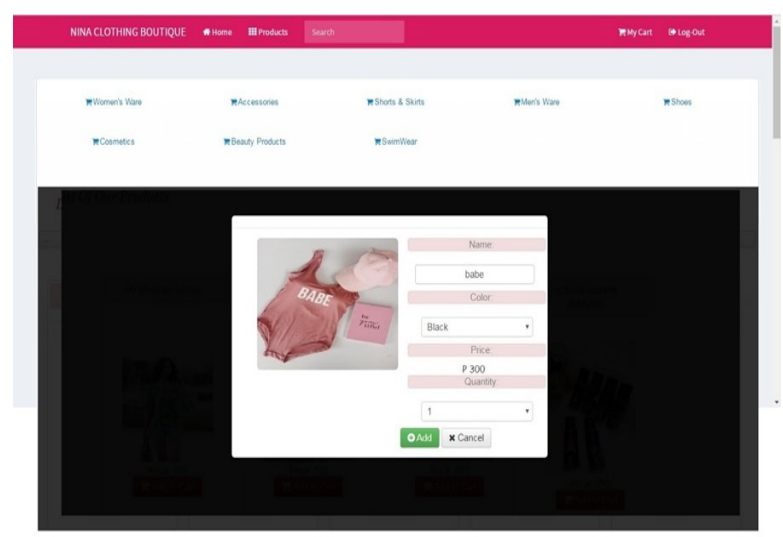

Figure 16 Ordering of product

The figure above shows the ordering of product, if the customer wants to order just click the "add to cart" and the admin will see it on his/her account.

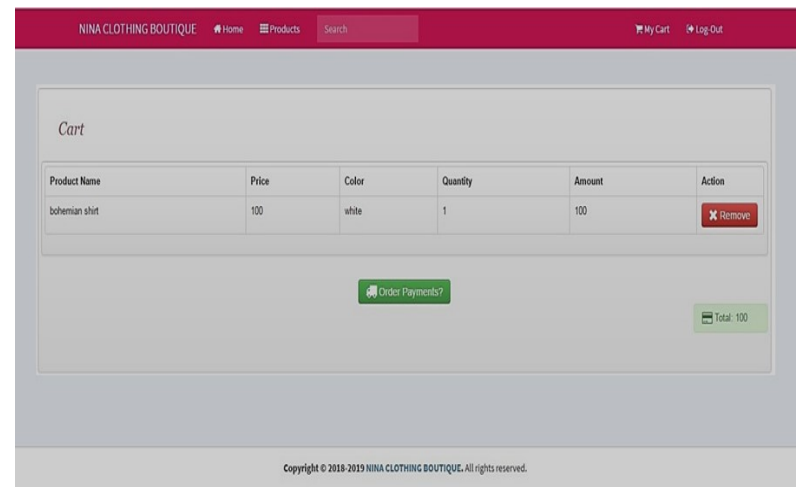

Figure 17 Cart of the customers

The figure above shows the cart of the customers. In this figure he/she can show his/her order and he/she can remove the order if they don't want to buy it.

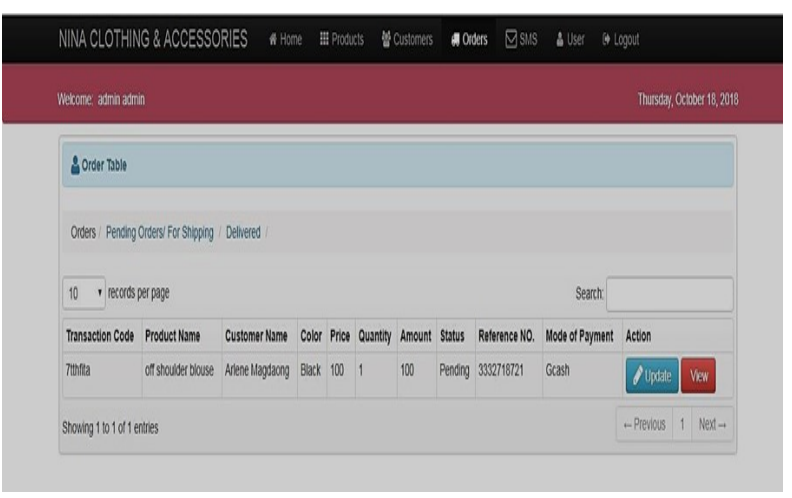

Figure 18 Admin Account Pending orders

The figure above shows the admin account pending orders. If the admin click the update status it will go to the shipping orders.

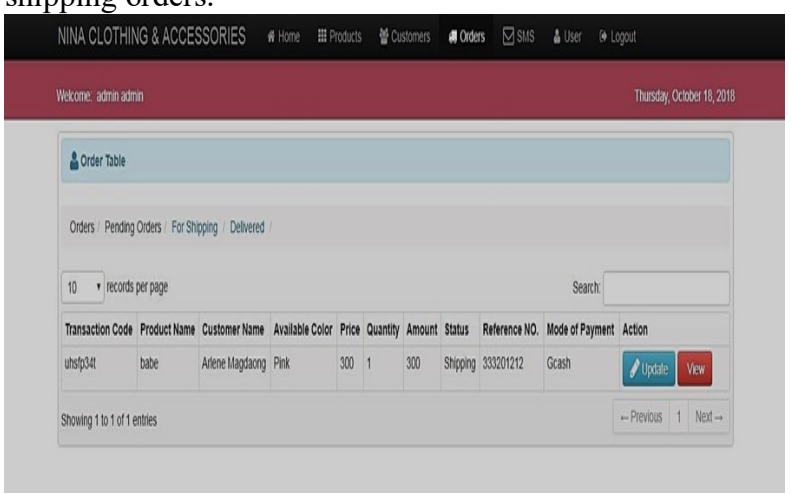

\section{Figure 19 Admin Account Shipping orders}

The figure above shows the admin account shipping orders. If the admin click the update status it will go to the delivered orders. 


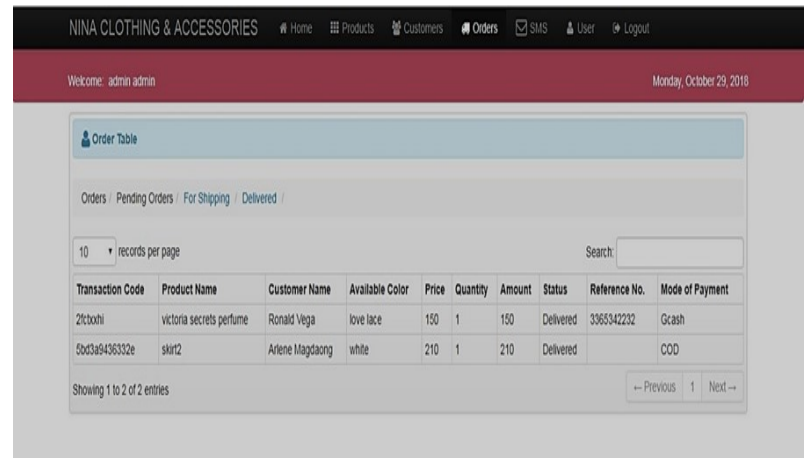

Figure 20 Admin Account Delivered orders

The figure above shows the admin account delivered orders. The admin was accepted the customer's order and ready for the delivery.

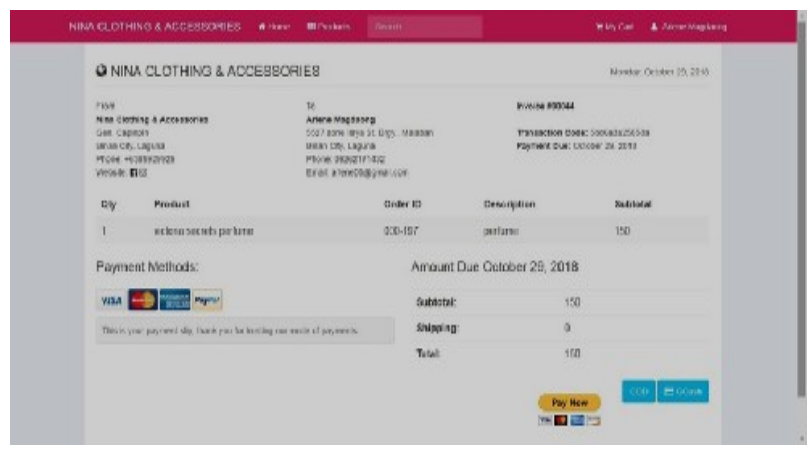

Figure 21 Payment Module of Customer

The figure above shows that the customer will choose any mode of payment he/she wants it can be thru G-Cash, PayPal or COD.

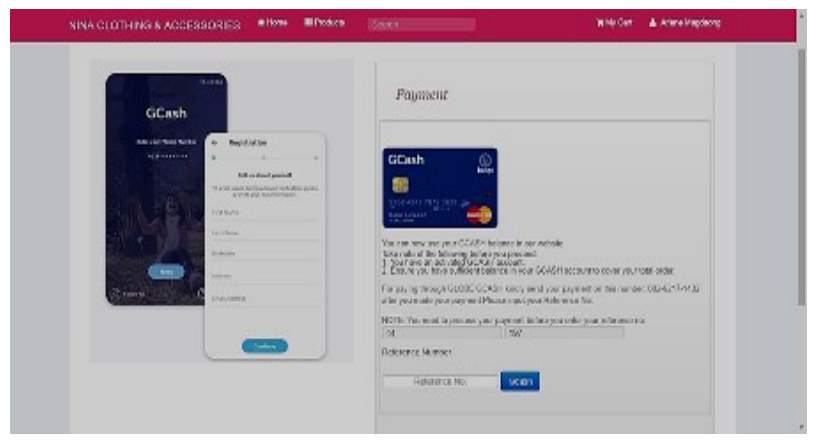

Figure 22 Payment Modules in G-Cash

The figure above shows that if the customer chooses the G-Cash she/he will input the reference number.

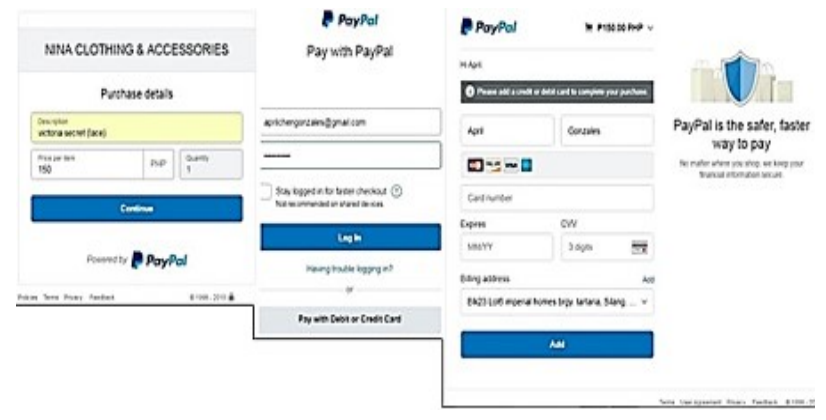

Figure 23 Payment Modules in PayPal

The figure above shows that if the customer chooses the PayPal she/he directed to PayPal and will input her/his account in PayPal to proceed to payment.

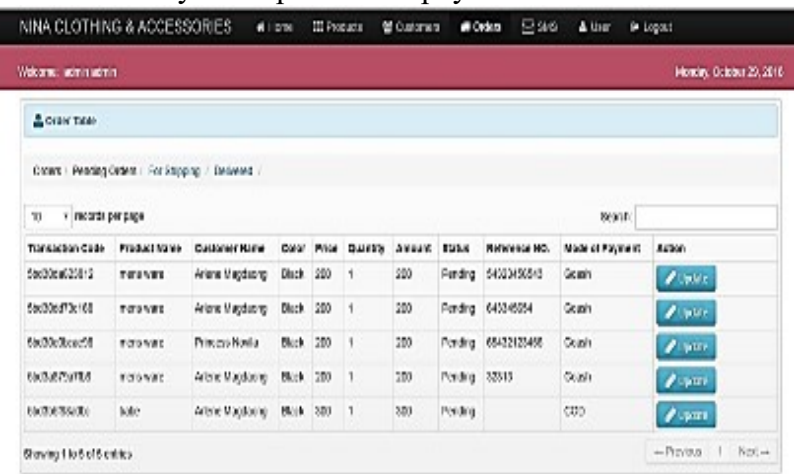

Figure 24 Payment Module of Admin

The figure above shows that the admin will know the reference no. of the customer's payment and the admin will update the status of the orders of the customer and it will add on the delivered orders.

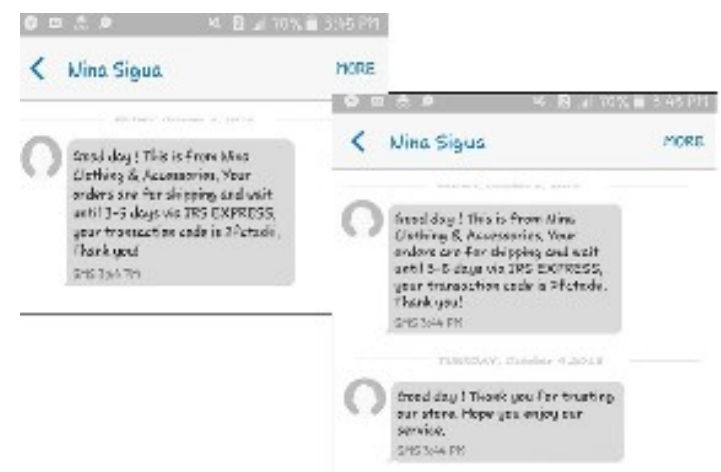

Figure 25 SMS Notification

The figure above shows that the customer receive a SMS from the admin that will notify the customer that his/her order is accepted and ready for the delivery. After the orders have been delivered, the customer will receive another text from the admin. 


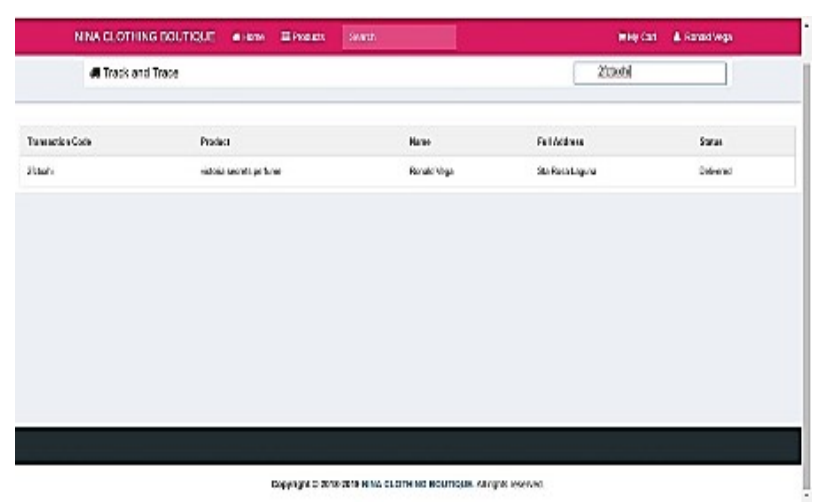

Figure 26 Tracking Module

The figure above shows that if the customer wants to track his/her order/s she/he needs to input the tracking number to the search bar and it will show the status of the order if it is ready to deliver or pending.

\section{CONCLUSION}

To ensure the customers that it will be easy to order through online and to ensure the admin that the system can generate the customer's product and their payment and the admin can send SMS on his/her customer.

\subsection{RECOMMENDATIONS}

The researchers of the study further recommended the following:

1. The system can also have the ratings to know if their customer was satisfied in their product.

2. It can also be applied to be an Android Application.

3. Customers or buyer can pay through bank transaction.

4. The system can also have reports every month.

\section{REFERENCES}

[1] Wenjing Yang "Analysis on Online Payment Systems of E-Commerce," autumn 2017.

[2] Jeeom Moeej "Online Reservation and Billing System with SMS Notification," 7 October 2015.

[3] Oludare Olaleye, Ayodele Olaniyan, Olalekan Eboda, Adeleke Awolere "SMS-Based Event Notification System," 2013.

[4] Lance Edion Maneja, Tyrone Harvey Tenorio,Luzviminda Tolentino"Online Reservation System and Ordering System for Don Juanboodle House with Sms Notification," Computer Studies Lemery Batangas. 